\title{
Skill development through a lead example driven curriculum
}

\author{
Markus Dumschat, Ralf Stetter, Joachim Rottmann \\ University of Applied Sciences Ravensburg-Weingarten, Germany \\ University of Education Weingarten, Germany
}

\begin{abstract}
Observations made at the RavensburgWeingarten University (RWU), have shown that interdisciplinary students entering the first semester face major challenges, particularly in the STEM (science, technology, engineering and mathematics) fields. Field investigations have identified two significant indicators for these difficulties: abstract teaching contents and missing links to their later application.

To overcome this, an interlinked curriculum was introduced at the RWU, where a "lead example" leads the teaching. The key objective is to improve the reflective, practice- and problem-oriented learning in order to strengthen the competencies of the students. To consolidate their understanding of the educational content, the "lead example" is integrated throughout several courses, depending on the lecture priorities. There is a continuous exchange between theoreticalknowledge teaching and problem-oriented learning, so that student motivation is improved, as well as, their ability to implement and reflect upon what they have learned in a more effective way.
\end{abstract}

\section{Introduction}

Today, in Germany students begin studies with a diversified heterogeneous educational background [1]. This is evident in cognitive as well as in socioeconomic and ethnological terms and it illustrates at the same time the heterogeneous ways to study. It is often the task of higher education institutions to compensate differences in learning levels and lack of study skills in the introductory phase of study.

In combination with the increasing digitization and use of new media, major challenges for modern university teaching arise. However, media diversity also offers opportunities to meet with different learning behavior of students by the selection of suitable teaching materials. New teaching materials are required in order to connect and communicate the continuously growing knowledge from theory and practice in a didactically meaningful way.

Therefore the RWU is participating in an innovative teaching project, called "WILLE - Wissenschaft lernen und lehren".

\section{Problem Statement and Analysis}

Various observations at the faculty of mechanical engineering have shown, that students in the first semesters have difficulties with their learning behavior, self-organization and the engineeringscientific perspective on problems. The transition to the university is a major challenge for these students. Quite a few of them fail, which is reflected in increasing numbers of dropouts, especially for Universities of Applied Sciences [2].

In addition to "learning and performance problems" the "lack of study motivation" seems to be the second most common reason for an early study termination [3]. According to Derboven, especially in engineering studies, isolated theoretical knowledge with a lack of professional relevance and practical examples demotivate students [4]. Links between the content of teaching and the later professional field are often hardly visible, because of too less practical examples and a missing relevance of teaching content for the later occupation. Also the use of scientific formulas without a specific understanding of the usability leads to a loss of motivation among the students.

The project of the RWU is based on different empirical studies, including the research of the student's motives for their study, as well as their motivation in the basic subjects, the visibility of links in these basic subjects, the use of educational materials and the impact on self-directed learning of students.

Heublein et al. speak of a heterogeneity in the motives of the study choice. At the same time, however, the various reasons for choosing a course also reflect, to a certain extent, the subject identification and expectations of the students [5]. According to Heublein et al., extrinsic motives are emphasized more in the choice of studies and that although a strong identification with the subject is such an important component for the successful completion of the study [5]. In order to reduce the increased probability of a dropout for primarily extrinsically motivated students, it could be one possible approach to reduce the dropout by measures which increase the interest and the identification with 
the course contents in the introductory phase of the study.

In addition, own studies on the courses also showed that there are differences in applicability of the learned knowledge and the abstractness of the respective lecture. Especially in the field of material science, the analysis indicated that for the surveyed students the contents of the lectures are closer to the application and thus the applicability of the learned knowledge is more comprehensible for the students.

It is assumed that students with training can better identify with, as well as access the abstract elements of this lecture by combining it with previous and practical knowledge [6].

Interviews at the RWU, conducted at the end of the last three semesters with a cohort of about 15 mechanical engineering students from the second semester, showed that there is a difference by the students in the use of teaching and learning materials and in the accepting of the methods, which are used by the teachers. Across the board, the type of student learning behavior revealed that there was a clear heterogeneity regarding learning/working behavior, motivation and teaching/learning materials for the follow-up. In the interview, the students were also asked about the characteristics that a lead example should have. This revealed that a lead example must be innovative and technologically demanding, and adapted to the age group, as well as being compact, tangible and easy to understand. It is important for the students to have a regular presence over the semester as well as the integration into all courses. Here, the desire was frequently expressed for consistency with possibly further examples. When asked for alternative lead examples, the vehicle was often cited, especially with an internal combustion engine. By investigating why students in the undergraduate studies would like to deal with this more closely, it turned out that a car is an everyday object which is present everywhere and depending on the mark and model, arouses emotions in the students, which apparently play an important role to them. As an example, the comparison between a large-displacement V8 engine and a very quiet, electrified car was mentioned.

This statement of the interviewed students correlated with observations of lecturers from RWU, who noted that the students prefer the chainsaw with the combustion engine in front of the electric motor chainsaw. According to the students, the type of integration also seems to play an important role in terms of acceptance. Here, the majority of all respondents put a considerable emphasis on authenticity in the chosen lead example as well as in concrete tasks which come from the real engineer field of responsibility. It is all the more understandable why the students consider the development project, which is taking place at the end of the second semester, as an important completion of the courses. This is because students have the opportunity to apply, enhance and expand their acquired knowledge in a constructive project in which they have to develop or optimize a real component of the chainsaw during a whole semester.

\section{Linked lectures and competencies}

A prominent requirement to enhance the key competencies of the students is indicated by studies concerning the competence of graduates of engineering schools [7]; in this frame of reference competencies are understood as more than just knowledge and skills. These competencies involve the capability to meet complex demands, by exploiting and mobilizing psychosocial resources which include skills and attitudes.

Through educational policy efforts (e.g. Bologna Process) "to focus the study more on occupationally utilizable competences and clearly defined learning outcomes" [8], the competence-oriented design of teaching and learning interests has found its way into university teaching.

Students of engineering courses need to dispose of a wide range of competencies in order to be able to deal with the complex challenges of current product development and production processes. This wide range of competencies which enable an independent acting can be arranged into four categories called key competencies:

- $\quad$ social competence

- $\quad$ self-competence

- methods competence

- $\quad$ subject-specific competence

Each of these categories dispose of a specific focus, all categories are interrelated, and collectively they form a basis for the further development of engineering curricula. The importance of "competencies to act", as a superordinate concept of the abovementioned competencies, lies in the ability of aspiring engineers to act purposefully and taskoriented. It does not only mean the ability to act, but also the use of learned knowledge, social norms and logical considerations to use thoughtful and efficient thinking about considerations and decisions to act responsibly.

For example, the ability to apply existing knowledge to new problems in order to solve these problems, are an important part of the methods competence, why in addition to a gradual enhancement of the capacity for abstract, the lead example should show the students, which processes play a role in the development of a technical products and which teaching contents can be assigned to these processes. The lead example shows how broad the knowledge spectrum can be as an engineer with only one product and on the other, why supposedly 
uninteresting subjects have their entitlement to study. In order to make the relevance of the study contents more recognizable for later working life, the lead example establishes links between lectures and practical applications.

After various investigations a chainsaw has been selected as a suitable lead example. In Figure 1 the linking of the courses is shown.

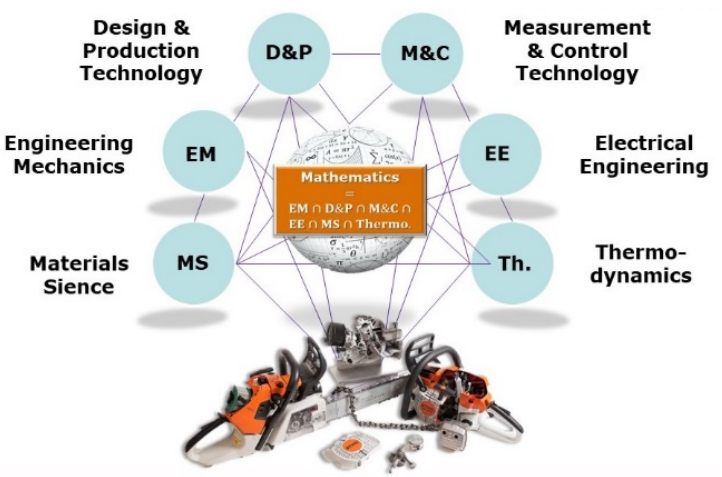

Figure 1. Linking the lectures based on the lead example „chainsaw”

Besides the chainsaw allows a linking of competences as well as a reflection of different teaching contents and an abstraction of the basic knowledge to a practical example. More advantages of the chainsaw are the compact design and the resulting possibility of a demonstration in the lecture hall.

\section{Didactic Concept to avoid "inert knowledge"}

As a result of the Bologna reform, the university's focus has shifted. It has gone from a purely academic teaching, to a teaching with the mediation of "scientifically based competence for future occupational fields of action" [9]. In recent years, although the universities have partially focused their attention on vocational orientation with the appropriate competence, but according to Gruber, Mandel \& Renkl usually still rather "inert knowledge", is mediated. This will allow the students to pass exams, but they will not be able to solve realistic, complex problems, as Gruber, Mandel, and Renkl clearly suggest [10]. On the one hand, metacognitive deficits are crucial for students not being able to use knowledge descriptively and meaningfully in case situations, on the other hand, motivational deficits can also be crucial for students if lectures are too theoretically so that the students lose their interest in relevant topics and appropriate knowledge is not available as needed.

By designing the didactic model, which is used to link the curriculum, the demand of the students for a diversification of teaching materials, a stronger linking between theory and practice and teambuilding activities were considered and continuously adapted to the lead example. The didactic concept founding on this project follows the constructivist, holistic, actionoriented learning approach and is primarily oriented at the method of problem-based learning. In problembased learning (PBL) real problems from the student's future professional field are used in teaching and learning processes.

The problems should be solved most independently by the students [11]. The complex, realistic problems serve as cognitive and motivating incentives for the learning process. By networking different teaching contents, interdisciplinary competence development can be further promoted. For example Stetter et al. showed, that students in the interdisciplinary project "formula student", where they build student racecars by their own, can better reflect and implement scientifically teaching contents [12].

Statements of the interviewed students also confirm this. Through the gradual transition from problem-based learning to methods of "pure" knowledge transfer, the learning conditions for students of the first semesters should be improved (compare Figure 2).

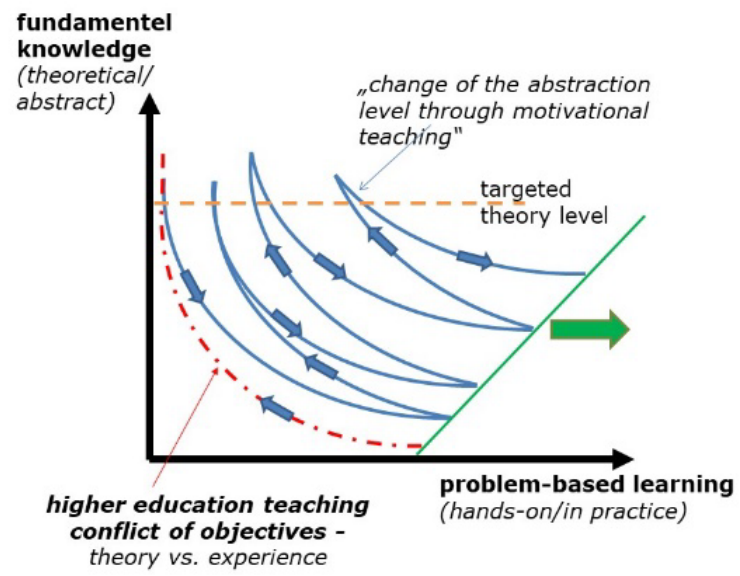

Figure 2. Continuous transition of theory and practice teaching in the basic studies

A high quantity of problem-based learning should promote intrinsic motivation as well as personal, methodological and social competences. With a gradual reduction of the concrete practical part, the abstract theoretical part of the lecture increases to the desired theory level. By the continuous transition between fundamental knowledge and problem-based learning the learned knowledge should be solidified with the help of job-related exercises. It is the aim, that this knowledge can be used at the next lecture by a kind of reminders on the basis of the lead example and bring out a shift in the level of abstraction.

After Renkl and in addition to a better applicability and a higher basic level, the intrinsic motivation of undergraduates should be further increased, especially 
in abstract subjects such as mathematics, technical mechanics and thermodynamics [13]. This should help to increase the self-directed learning of the students, too.

\section{Implementation into the curriculum}

The findings of the field examination serve the development of didactically adapted, multimedia teaching materials for the improvement of teaching at the RWU. The materials are developed for different learning types and oriented to the lead example.

In the course technical mechanics (statics), for example, the calculation of the center of gravity will be taught through the chainsaw (Figure 3).

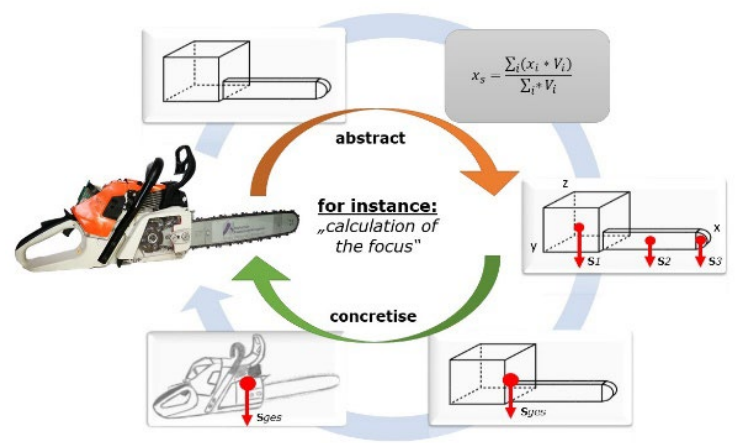

Figure 3. Problem-based learning by the example of technical mechanics

Mathematics as well as technical mechanics offer methods for calculating the center of gravity. These cross-connections help to link the lectures.

By taking into account that a task only becomes a problem when certain boundary conditions are incomplete or even contradictory, whereby the task becomes a certain complexity, the method of problem-oriented learning is used [14]. As a prospective engineer, students must be able to analyze a problem from an engineering point of view and make sensible assumptions about missing sizes, which is often the case in the initial launch of products.

According to Riedl the retention performance can be increased by addressing various sensory channels (read, hear, see, speak, act) [15].

During the lecture the students have the opportunity, through suitable hardware of the lead example, to compare the calculated values of the center of gravity with haptic perception. After Weinert motivational, volitional and social competences should also mediated through concrete extracurricular relationships to internalize the holistic approach of the engineering-scientific and mind-set [16].

For example events at the beginning and during the semester like a product demonstration (Figure 4) or the student's possibility to research a product in a computerized reality, are implemented. These should arouse student's curiosity about "mechanical engineering" through direct contact with the lead example and should help to increase the student's intrinsic motivation.

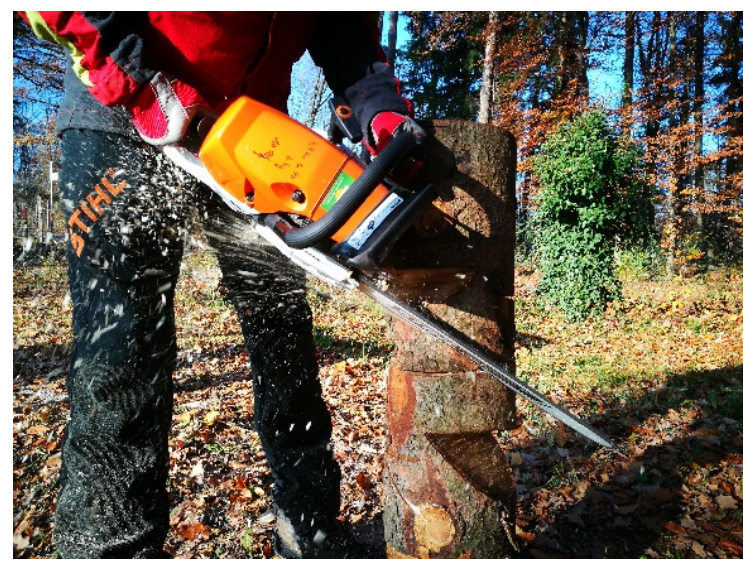

Figure 4. Product demonstration at the beginning of the semester by forestry expert

Students should be able to visualize the significance of mechanical engineering in the past, present and future and to rethink their partly primarily extrinsic motives for taking up the studying.

Unfortunately, the time which the students spent in lectures and tutorials is limited. Consequently, it is nearly impossible to alter the form of education in every lecture in order to enhance key competencies. Thus, a promising possibility to integrate the efforts aimed at supporting the development of key competencies was identified: the parts of the curricula that were already different from other part of the curriculum - the projects intended to learn engineering design.

\section{Development Project}

Several internationally recognized educators and researchers agree that teaching engineering design is the most challenging and simultaneously the least straight forward part of the curricula in engineering studies [17]. Evans et al. [18] specify: [engineering design] "seems to occupy the top drawer of a Pandora's box of controversial curriculum matters, a box often opened as accreditation time approaches". The general insight that the most promising form to teach engineering students the ability to design (not theoretical knowledge about design) are realistic, open ended problems to be solved in teams, i.e. project based learning, is stated in several publications [e.g. 17, 19]. The central characteristic of this kind of design projects is that they lead to experiences in accordance to Kolb's model of experiential learning [20].

As part of the so called development project, a practice-related task is performed by the students. The 
goal is a simple, possibility to start a chainsaw. The importance of this goal is illustrated during an introductory kick-off meeting with forestry experts. The importance of poor starting behavior and its effects are not only demonstrated, but also tested by the students.

The methodological material selection takes place with the help of the CES EduPack, which provides a comprehensive database of materials and process information and can be visualized depending on the exact boundary conditions. Students are encouraged to contribute to their learning by defining requirements and boundary conditions, as well as commenting on the sustainability of their materials selection.

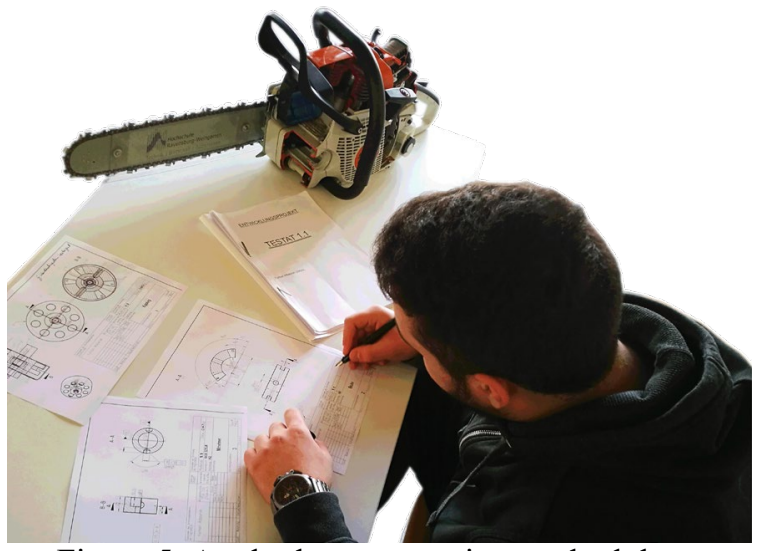

Figure 5. Apply the construction methodology

Finally, students prototype their solution using additive manufacturing (Figure 6). In the course of regular project meetings, results and prototypes are presented and discussed with the forestry experts.

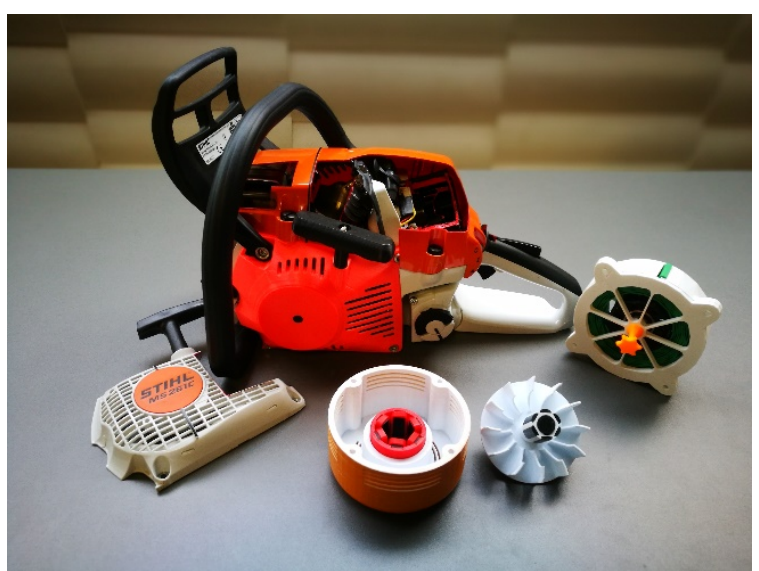

Figure 6. Additive manufactured student solutions

This interdisciplinary teaching concept promotes the connection and comprehension of key engineering competences such as mechanical design, material science and advanced mathematical concepts with the real end users' problems.

\section{Conclusion}

In order to improve the teaching in the field of mechanical engineering at the RWU, a new concept is currently being applied to reduce the abstractness of the basic subjects by integrating a lead example in teaching. Through the targeted transition from practice (e.g. problem-based learning) to theory (basic mediation) and vice versa, the lead example is intended to improve a gradual transition between the capacity for abstract and an engineering-scientific mind-set. Regular evaluations, continuous quality assurance procedures and the inclusion of the latest research results serve to develop a didactic concept with adapted, diversified teaching materials. The lead example is broken down to individual learning modules and contributes to connect the curriculum of the university.

Through enthusiasm the lead example is intended to increase the intrinsic motivation of students in the undergraduate studies and provide above all, in addition to critical thinking and the teaching of skills, a strong basis for their further study.

First research results have shown that the lead example is mainly positive perceived by the students and that there is a demand for a stronger presence and further lead examples. The so called "red line", which is drawn by the lead example through the undergraduate studies, helps the students to establish links between the lectures and the teaching contents.

\section{References}

[1] R. Schulmeister, C. Metzger and T. Martens, „Heterogenität und Studienerfolg. Lehrmethoden für Lerner mit unterschiedlichen Lernverhalten", Paderborner Universitätsreden, P. Freese (ed.). Online available at:

http://www.rolf.schulmeister.com/pdfs/zeitlast_pur.p df, retrieved January 23, 2018.

[2] U. Heublein, Presentation on „Aktuelle Entwicklungen beim Studienabbruch Herausforderungen für Lehre und Beratung“" Symposium: ,, Wie viele Studienabbrecher *innen will sich unsere Gesellschaft leisten? “, Stuttgart, June 15, 2018.

[3] HIS Hochschul-Informations-System GmbH, „Leistungsprobleme als subjektive Begründung des Studienabbruchs“, VDMA Abbrecherstudie ausgewählte Grafiken, VDMA. Online available at: http://www.vdma.org/ documents/105628/211099/09-1209\%

20VDMA_Abbrecherstudie_Grafiken.pdf/fdf $3 \mathrm{f0de}-$ f384-40a3-9394-2d8ed3c38e26, retrieved February 25, 2018. 
[4] W. Derboven, G. Winkler, „Ingenieurwissenschaftliche Studiengänge attraktiver gestalten “, Springer, Berlin/Heidelberg, 2010, p. 19, cf. Table 2.2.

[5] U. Heublein, G. Besuch, C. Hutzsch, J. Schreiber, D. Sommer, „Zwischen Studienerwartungen und Studienwirklichkeit - Gründe für den Studienabbruch. Ergebnisse einer bundesweiten Befragung von Exmatrikulierten in Maschinenbau-Studiengängen. ", Impuls-Stiftung, Stuttgart, 2009, p.38-39, cf. Fig. 4.1.

[6] M. Dumschat, R. Stetter, A. Kaufmann, J. Rottmann, „Vom Konkreten zum Abstrakten Wissensvermittlung anhand eines Leitbeispiels", Tagungsband zum 3. Symposium zur Hochschullehre in den MINT-Fächern, B. Meissner, C. Walter, B. Zinger (ed.), Nürnberg, 2017, p. 55-62.

[7] D.S. Rychen, L.H. Salganik, M.E. McLaughlin (eds.),"The Definition and Selection of Key Competencies - Executive Summary”, OECD, 2005.

[8] Hochschulrektorenkonferenz (HRK),

„Fachgutachten zur Kompetenzorientierung in Studium und Lehre“, HRK, Berlin, 2012, p.10.

[9] K.-H. Gerholz, P.F.E. Sloane, „Lernfelder als universitäres Curriculum? - Eine hochschuldidaktische Adaption“, bwp@ Berufs-und Wirtschaftspädagogik - online, No. 20, p.1-24.

[10] H. Gruber, H. Mandl, A. Renkl, ,Was lernen wir in Schule und Hochschule: Träges Wissen?", Die Kluft zwischen Wissen und Handeln: Empirische und theoretische Lösungsansätze, H. Mandl, J. Gerstenmaier (ed.), Hogrefe, Göttingen, 2000, p. 139156.

[11] I. Ulrich, ,Gute Lehre in der Hochschule Praxistipps zur Planung und Gestaltung von Lehrveranstaltungen “, Springer Fachmedien, Wiesbaden, 2016, p. 223.
[12] R. Stetter, M. Till, P. Eckart, "Concept for a Modular Rave-Car-Frame for Conventional, Hybrid and Electrical Applications", Proceedings of the Fisita EAEC Conference, Valencia, 2011.

[13] A. Renkl, „Lernen durch Lehren“, Deutscher Universitätsverlag, Wiesbaden, 1997.

[14] B. Zinn, U. Faßhuber, „Ein problembasiertes Lernszenario aus der Perspektive von Studierenden", ZFHE Jg. 7/ No.3, T. Brahm and D. Euler, St. Gallen, 2012

[15] A. Riedl, „, Grundlagen der Didaktik“, Franz Steiner Verlag, Stuttgart, 2004, p. 137.

[16] F.E. Weinert, „Vergleichende Leistungsmessung in Schulen - eine umstrittene Selbstverständlichkeit", Leistungsmessungen in Schulen, F.E. Weinert (ed.), Beltz Verlag, Weinheim und Basel, p. 27ff.

[17] C.L. Dym, A.M. Agogino, O. Eris, D. Frey, L.J. Leifer, "Engineering Design Thinking, Teaching, and Learning", Journal of Engineering Education 1, 2005, pp. 103-120.

[18] D.L. Evans, B.W. McNeill, G.C. Beakley, "Design in Engineering Education: Past Views of Future Directions", Journal of Engineering Education, Vol. 69, No. 4, 1990, pp. 517-522.

[19] A.H. Hoffman, K.N. Liadis, B. Boettcher, "Work in Progress - Developing a Project Based First Year Design Course", Proceedings of the 35th ASEE/IEEE Frontiers in Education Conference, Indianapolis 2005.

[20] D.A. Kolb, "Experiential Learning. Experience as the Source of Learning and Development", Prentice-Hall: 1984. 